\title{
Klares «Ja» zur Delegiertenversammlung
}

\author{
Im Solothurner Landhaus schafft sich die Präsidentenkonferenz selber ab
}

Lii. Eine schlankere, arbeitsfähigere und flexiblere FMH, und damit letztlich eine stärkere Ärzteschaft: Das sind die Hauptziele der laufenden, internen Strukturreform. Nach der konsultativen Arbeitstagung der Mitglieder der Ärztekammer im «Stade de Suisse» und der anschliessenden breiten Vernehmlassung hat die Präsidentenkonferenz jetzt in Solothurn wohl wegweisende und klare! - Grundsatzentscheide gefällt.

Konkret gehe es darum, zuhanden der Ärztekammer von Anfang Dezember ein Modell für eine Statutenänderung zu schaffen, sagte FMHPräsident Jacques de Haller zu Beginn der gutbesuchten Konferenz. Am Ende des Tages lag eine solche Vorlage auf dem Tisch: Die Synthesen, die aufgrund der Vernehmlassung bei den einzelnen Gesellschaften entstanden waren, wurden praktisch alle mit grossem Mehr gutgeheissen.

\section{DV statt PK}

Klar sagten die anwesenden Präsidentinnen und Präsidenten «Ja» dazu, dass eine Delegiertenversammlung (DV) ihr eigenes Gremium - eben: die Präsidentenkonferenz - dereinst ersetzen soll. Ebenso klar manifestierten sie aber auch ihren Willen, dass die Ärztekammer ihre Kontrollfunktion behält und ihr deshalb ein Rekursrecht gegen die Beschlüsse der DV zugestanden wird. Abgelehnt wurde ein Kontrollrecht der Ärztekammer über die Mitglieder der DV.
Viel zu reden gab die Zusammensetzung der DV: Die Zahl der Delegierten wurde auf zwischen 25 und 32 festgelegt, Genaueres wird die Ärztekammer zu entscheiden haben. Die Sitze sollen nach einem fixen System in der vorgeschlagenen Form verteilt werden.

\section{Nur ein Präsident}

Zweiter umstrittener Hauptpunkt war die Frage, ob es weiterhin einen FMH-Präsidenten geben soll oder ob die Ärztekammer oder die neu zu schaffende DV ihr eigenes Präsidium erhalten sollen. Auch hier resultierte eine klare Zustimmung zur «schlankeren» Variante, also für einen einzigen Präsidenten.

Bereits in der Vernehmlassung unbestritten waren eine Amtszeitbeschränkung für Mitglieder des Zentralvorstandes und die Schaffung einer Geschäftsprüfungskommission. Auch ist man sich einig, dass es die neuen Statuten als unvereinbar bezeichnen müssen, dass ein Mandat im Zentralvorstand oder in der neuen Delegiertenversammlung mit einer Verantwortung in einer aktiven kommerziellen Unternehmung im Gesundheitsbereich einhergeht.

Alle Beschlüsse der Präsidentenkonferenz werden jetzt in einen konkreten neuen Statutenentwurf eingebracht, der in der ausserordentlichen Ärztekammer vom 2. Dezember 2005 Gegenstand einer vertieften Diskussion sein wird. 